\title{
PILE SETTLEMENT INDUCED FROM SOIL MOVEMENT DUE TO BREAKDOWN OF RETAINING WALL
}

\author{
RAJESh PRASAd SHUKLA
}

\begin{abstract}
Adani Institute of Infrastructure Engineering, Department of Civil 8 Infrastructure Eng., 382427 Ahmedabad, India

correspondence: rpshukla.2013@iitkalumni.org
\end{abstract}

\begin{abstract}
Very few studies measured the settlement of retaining wall supported piles foundation under a soil movement. This study explores the pile settlement induced from the sudden breakdown of a closely located retaining wall using a small-scale experimental model. Various factors affect the pile settlement, but the influence of the embedment ratio of the pile and collapsed height of the retaining wall is relatively more visible. The induced settlement decreases with pile embedment depth and increases with the collapsed height of the retaining wall. The pile settlement initially increases at a higher rate with an increase in the collapsed height to a certain extent, beyond which, becomes relatively less observable. Pile group settlement reduces with the increase in spacing and the number of piles in longer piles. However, opposite trends have been observed in piles with a smaller embedment ratio. The settlement reduces logarithmically with the increase in the distance between piles and the retaining wall. Pile groups with small embedment ratio are severely more affected by the breakdown of the retaining wall than the piles of a large embedment ratio. Pile groups placed parallel to the retaining wall are more affected than those placed orthogonally.
\end{abstract}

KEYworDs: Collapse, piles, retaining wall, settlement, soil movement.

\section{INTRODUCTION}

A pile foundation is a deep foundation, commonly used when soil is loose at shallow depth, structural loading is large and under various other adverse conditions. Piles foundation can be subjected to a variety of loadings, such as lateral, vertical and combined loading. Based on the mechanism of load transfer, laterally loaded pile foundation is divided into two classes; passive and active [1. Piles transferring the loads to the soil are active piles, and piles sustaining the lateral loads induced from the soil movement are passive piles. The loading on passive piles derives due to the soil movement induced from mining, soil liquefaction, constructions activities, landslides, tunnelling and several other human activities [2]. In metropolitan cities, new structures are frequently constructed near to an existing one. A large volume of soil is excavated for carrying out new construction, which induces soil movement and changes the prevailing soil stresses. Lateral loads generated by the soil movement causes additional deflections, settlement and bending moment in piles located close to the construction site, which may further reduce the structural integrity of the piles 3 .

A number of field studies are reported in the literature describing the degradation of stability of pile foundations due to the excavation of soil [3]. Apart from these field studies, a good number of theoretical and experimental studies were also carried out to determine the pile behaviour subjected to excavation induced soil movement [8] 20]. Leung [16] predicted the behaviour of a pile under the lateral movement of the retaining wall and observed significant plastic flow and increased deflection compared to a stable retaining wall. These studies determined the pile's response in term of lateral displacement and induced bending moment. A detailed review of work on passive piles was presented by Uge and Cheng [21]. Pham et al. 22] observed that the lateral capacity of a pile group in cohesive soils was reduced by increasing the spacing (s) from $\mathrm{D}$ to $2 \mathrm{D}$, but further increase in the spacing increases the lateral capacity. CPT data can be correlated to the load-carrying capacity of piles [23]. Li et al. 24] evaluated the soil displacement as well as induced bending moment induced on a single pile placed adjacent to an excavation using CPT data. Malhotra et al. [25] determined the reduced capacity of the pile resulting from lateral movement of soil. Zhang [26] presented an algorithm to determine the additional bending moment induced by soil movement. A number of other studies, which determined the effect of tunnelling induced soil movement on pile behaviour. However, the effects significantly differ from those caused by excavation.

Though an excavation can induce both the lateral displacement and settlement in the pile foundation, only a few studies considered the settlement of piles 27-30. Jacobsz et. 27. measured the surface settlement due to tunnelling. The influence zone was identified, where piles are vulnerable to settlement. Zhang et al. [28] used a 'Double-Spring' model and revealed that an increase in the axial load increased the settlement of the pile group under the vertical movement of soil. Shukla and Patra [29] measured 


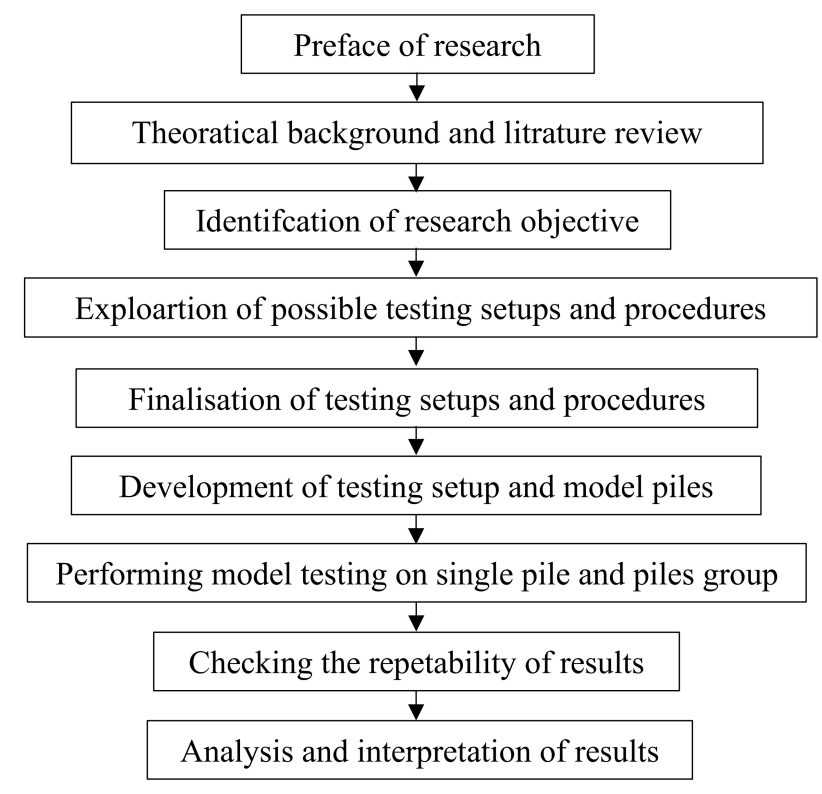

FiguRE 1. Research methodology flow chart.

the settlement of axially loaded pile groups for different conditions. The results were presented in the respective units; consequently, the results cannot be used directly. Shan et al. 30] assumed piles group as a pier and found that settlement increased with an increase in the group spacing.

The literature review stipulates that a significant number of studies determined the lateral deflection of retaining wall supported piles, subjected to soil movement. A very few recent studies attempted to find out the settlement of piles under soil movement. Most of the studies assumed retaining wall to be stable. However, the retaining wall constructed to support the pile can fail itself under various circumstances. This situation can easily arise in the hilly regions, mining regions and in metropolitan cities, where the retaining wall may fail due to deep slopes failure, large volume excavation or due to other underground construction activities. Motivated by the research gap, the study determines the effect of the sudden collapse of the retaining wall on the settlement of closely located pile foundation through small scale model testing. First, the details of the experimental setup and the testing procedure are provided in detail. The results and discussion section describes the behaviour of single and piles group separately. The settlement of piles group is studied by varying pile embedment depth, spacing, piles number and relative location of piles from retaining wall. The flow chart describing the different activities followed in the present study is shown in Fig. 1.

\section{EXPERIMENTAL SETUP}

The testing setup is made up of a tank, model piles, a loading arrangement, measuring devices like dial gauges, a wooden shutter stiffened to a mild steel tank, small ancillary equipment and various other tools to get the experimental setup ready for the testing. Fig. 2 (not to scale) shows the schematic diagram of the testing setup and wooden shutter arrangement that has been used in the study. The tank is made of $6 \mathrm{~mm}$ thick plates of mild steel, stiffened at a different level to avoid any distortion to tank shape during loading stages.

A wooden shutter, consisting of foldable parts, was installed into the tank to simulate the abrupt breakdown of the retaining wall. The shutter was fixed to the tank wall using nut bolt arrangement. Each of the parts of the wooden shutter is linked together with the help of but hinges. These hinges are used such that each wooden shutter may rotate only away from the tank. Each wooden shutter is coupled to two columns attached to the tank walls through two hinges. Loosening of these hinges enables each shutter to drop independently without affecting bottom shutters or stable bottom part of the retaining wall. The details of the wooden shutter are presented in Fig. 2(b). The nominal collapsed height of the retaining wall $\left(H_{c}\right)$ is normalized with respect to the pile length $(L)$ and expressed as a ratio of the collapsed height of the wall to the length of the pile. The nominal collapsed height for three different heights $\left(H_{1}, H_{2}\right.$ and $\left.H_{3}\right)$ is presented in Table 1 .

The 'Ennore sand' was used to form the foundation bed. Its behaviour is free from environmental effects. The grain size distribution plot is shown in Fig. 3. It shows that the soil is uniformly distributed. The sand grains consist of angular shaped particles and are greyish-white in colour. The other index properties determined in the laboratory are shown in Table 2 Earlier studies found that group effects are more pronounced in cohesionless soils than in cohesive soils [31. Therefore, cohesionless soil was selected as the foundation soil.

The model piles are made of hollow circular aluminium tubes of $1 \mathrm{~mm}$ thickness and $30 \mathrm{~mm}$ internal diameter. The diameter of the piles was maintained constant throughout the testing. Piles of the length of $320 \mathrm{~mm}$ and $640 \mathrm{~mm}$ were used in the testing to consider the effect of embedment depth of piles on the settlement of piles group. The strain gauges were coupled inside the pile to measure the induced strains. Settlement and lateral displacement of piles group were measured through dial gauges 1 and 2 respectively. Dial gauges have a sensitivity of $0.01 \mathrm{~mm}$. Various other accessories and fastenings were also used to attach the pile cap to the pile, to attach the dial gauges at the chosen place and to detach the piles from the testing assembly.

\section{Experimental PROCEDURE}

All tests were carried out in a 1-g environment. Initially, the load-carrying capacity of piles was evaluated by compression testing. Based on the compression test results, the safe load-carrying capacity of the pile was determined. The compression tests were carried 


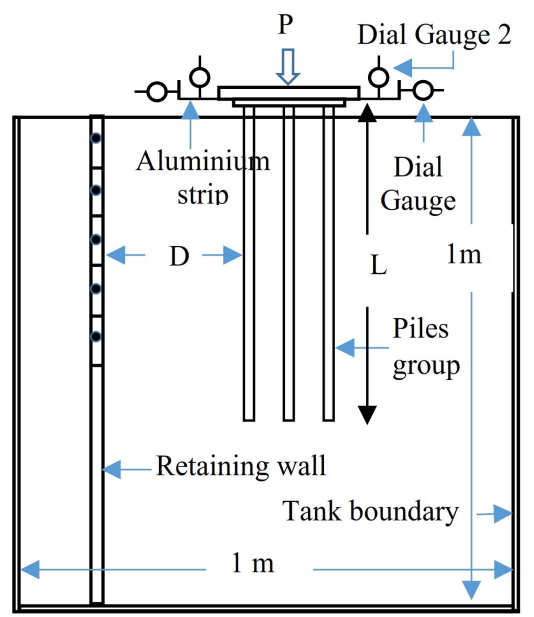

(a)

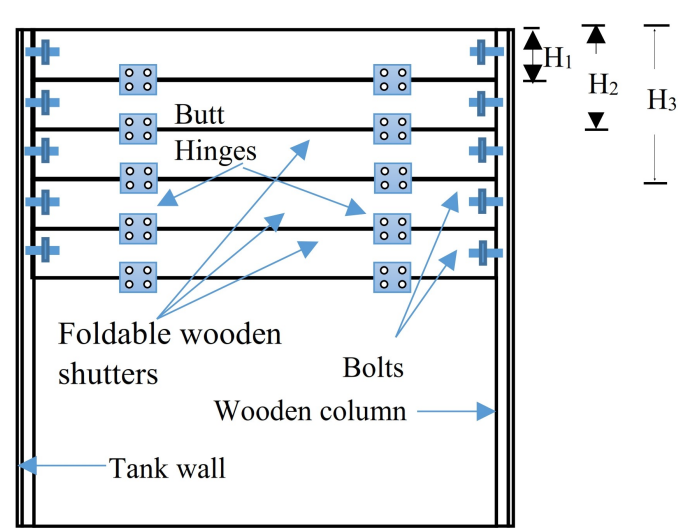

(b)

Figure 2. Research methodology flow chart.

\begin{tabular}{cccc}
\hline $\begin{array}{c}\text { Pile length } \\
(\mathrm{cm})\end{array}$ & Number of released wooden planks & $\begin{array}{c}\text { Collapsed height, } \\
H_{c}(\mathrm{~cm})\end{array}$ & $\begin{array}{c}\text { Nominal collapsed height, } \\
\left(H_{c} / L\right)\end{array}$ \\
\hline \multirow{3}{*}{32} & 0 & 00 & 0 \\
& 1 & 10 & 0.312 \\
& 2 & 22 & 0.687 \\
\hline \multirow{3}{*}{64} & 0 & 00 & 0 \\
& 1 & 10 & 0.156 \\
& 2 & 22 & 0.344 \\
& 3 & 34 & 0.532 \\
\hline
\end{tabular}

TABLE 1. The nominal height of the retaining wall collapsed.

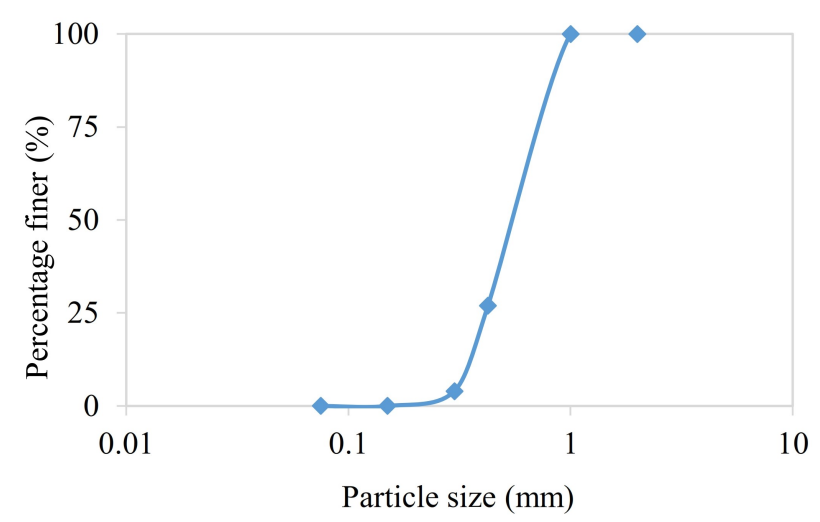

Figure 3. Grain size distribution of 'Ennore sand'.

out by applying vertical compressive loading on the pile cap in an incremental order. The settlement of piles was recorded with an accuracy of $0.01 \mathrm{~mm}$ for every loading increment. The maximal capacity of piles was then determined from load-settlement plots by the double tangent method. The safe load carrying capacity of pile groups was evaluated considering the factor of safety equal to two. Later, these loads were positioned on the pile group.

Rainfall method was employed to prepare the sand foundation bed of desired density. This technique has been already used by various researchers to attain desirable densities [8, 32. Piles were marked to a onethird length from the top and assembled to the pile cap. Marks were made on the tank walls to recognise the tip level of piles during the sand filling. The sand was filled just below the marked level (pile tip level) on tank walls, and piles were held at the prerequisite level into the tank using a number of steel plates and C-clamps. This stage involves the utmost care to retain the pile cap level in the loading stage. The level of the pile cap was checked to reduce any chance of tilting. Perfectly horizontal pile cap helps to apply the loads vertically on the pile before the breakdown of the retaining wall. The sand filling started again and continued until it filled the tank up to the marks on the piles. As piles were embedded adequately in the sand, plates were cautiously detached by releasing the $\mathrm{C}$ clamps. To make sure that the pile cap remains perfectly horizontal during the filling process, the level of the pile cap was checked intermittently and the sand filling was again continued up to just below the pile cap. Four dial gauges were attached at the pre-determined location using steel columns and two steel plates. Plungers of dial gauges, measuring the lateral deflection were positioned on $\mathrm{L}$ shaped iron strips attached on the pile cap. Plungers of other two dial gauges measuring the settlement of pile cap were 


\begin{tabular}{lclc}
\hline Property & Description & Property & Description \\
\hline Maximum density & $1.71 \mathrm{~g} / \mathrm{cc}$ & Angle of internal friction & 340 \\
Minimum density & $1.47 \mathrm{~g} / \mathrm{cc}$ & Pile soil friction & 20.50 \\
Unit weight & $15.61 \mathrm{kN} / \mathrm{m}^{3}$ & Uniformity coefficient & 1.70 \\
Relative density & $54.3 \%$ & Coefficient of curvature & 0.97 \\
Void ratio & 0.672 & Specific gravity & 2.64 \\
\hline
\end{tabular}

TABLE 2. Details of foundation sand used in the study.

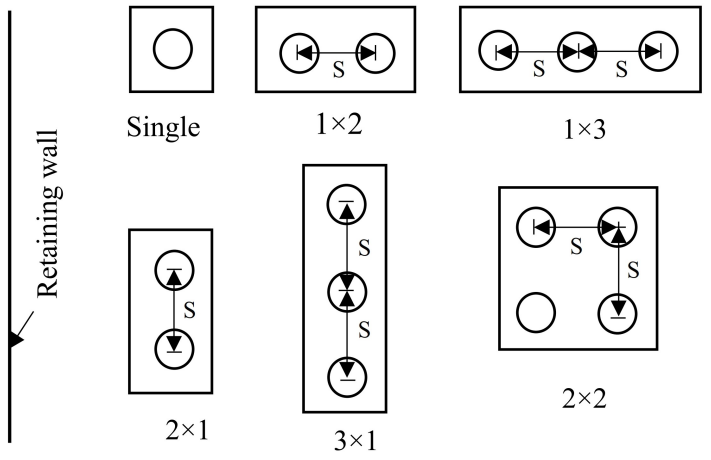

Figure 4. Pile groups configurations used in the testing.

positioned on the iron trip. Pile cap level was again checked before the application of loading.

Ultimate load-carrying capacity was determined by performing compression tests and the safe load was determined by considering the factor of safety to be 2.0. The safe load was applied directly on the pile's cap. To check the influence of the loading stage on soil density, the density of sand was determined before and after the loading stage. Most of the time, the load application does not change the soil density. The sand density was determined using a penetrometer. Before heading to the simulation of a collapse of the retaining wall, the whole setup was upheld idle for adequate time to allow the settlement of piles induced due to application of loading on the pile. The parts of the wooden shutter were released to simulate the abrupt breakdown of retaining structure. Dial gauge readings were recorded after the breakdown of the retaining structure (wooden shutter). Fig. 4 shows all four piles of group configurations used in the testing. Pile groups $1 \times 2$ and $1 \times 3$ are placed parallel to the direction of the soil flow, which is also perpendicular to the retaining wall.

\section{Results AND Discussion}

The response of piles foundation subjected to the breakdown of the retaining wall was measured and presented in the dimensionless form. The settlement $\left(S_{t}\right)$ and lateral displacement $\left(D_{l}\right)$ are normalised with respect to the collapsed height of the retaining wall $\left(H_{c}\right)$. The distance $(X)$ between the pile and retaining wall was normalised with respect to the length of piles $\left(H_{c}\right)$. The influence of the breakdown of a

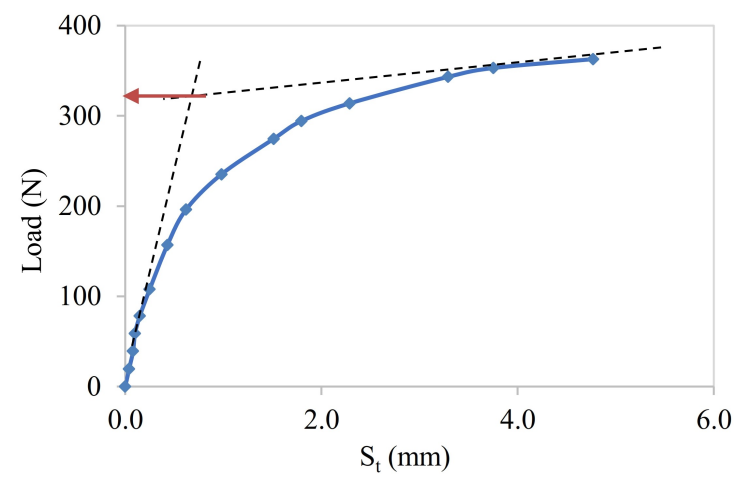

Figure 5. Load settlement characteristics for a pile of $L / D=10$.

retaining wall is discussed separately for single piles and piles group. Fig. 5 shows a typical load-settlement characteristic for a single pile of $L / d=10$. The ultimate load-carrying capacity of single piles is $0.315 \mathrm{kN}$ using the double tangent method (Fig. 5). Considering the factor of safety to be 2 , the safe capacity is $0.15 \mathrm{kN}$. Similarly, the ultimate capacity and safe load-carrying capacity for other pile groups were determined. Earlier studies revealed that load-carrying capacity increases even up to a spacing of $6 d$, and a further increase in the spacing make piles behaviour independent of spacing and behaves like an individual pile [33]. Considering this fact, spacing is increased up to $6 d$.

\subsection{Single Piles}

The effect of soil movement induced by the abrupt breakdown of the retaining wall on a single pile is shown in Fig. 6. The pile settlement and lateral deflection increase with an increase in the collapsed height, irrespective of other parameters. The induced settlement is relatively higher than the lateral displacement. The piles without loading show more lateral deflection and relatively less settlement. Mahmood and Abbas 34] also made a similar observation under cyclic lateral loading.

The settlement is varying from 1.2 to 4.5 times the lateral deflection of piles. The difference is maximum for pile with embedment ratio of 10 and located close to the retaining wall. However, increasing the embedment ratio from 10 to 20 reduces the difference in the lateral deflection and settlement drastically. The lateral deflection increases continuously with the height 


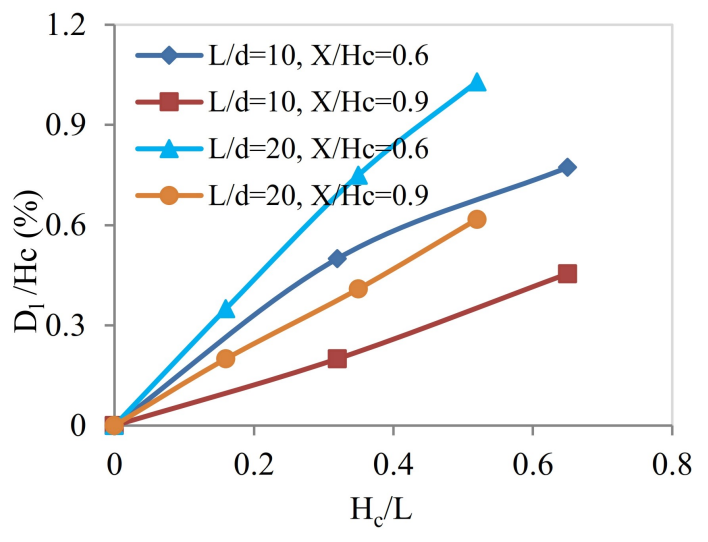

(a)

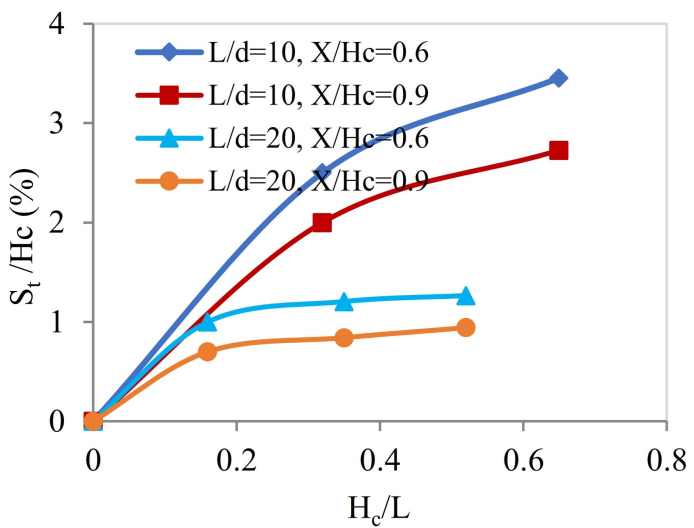

(b)

Figure 6. Pile response: (a) Lateral displacement, (b) Settlement.

of the collapsed retaining wall. However, the settlement increases initially with the collapsed height, but after a certain height, the effect becomes marginalised.

The measured settlement is significantly lesser in the case of the pile of embedment ratio 20 than for the piles of embedment ratio 10. It is due to the prevailing support from the lower part of the longer piles. The lateral displacement $\left(D_{l}\right)$ increases and settlement $\left(S_{t}\right)$ decreases with an increase in the embedment ratio. The capacity of the longer $(L / d=20)$ pile is more than the shorter pile $(L / d=10)$. Therefore, the moment induced due to the breakdown of the retaining wall is higher. This may have contributed to the higher lateral displacement observed in longer piles. The influence of the distance of the piles from the retaining wall is more apparent in the lateral displacement than in the settlement.

\subsection{Pile Groups}

The redistribution of moment and stress in the case of pile groups make behaviour very complex as compared to single piles. Therefore, most of the earlier studies explored the behaviour of the single pile only. The active pressure sharply decreases with the progressive rotation of the retaining wall in the upper part of the retaining wall, while the pressure reduction in the lower part is relatively lesser [35, 36]. In the present case, the active earth pressure reduces relatively more sharply due to the abrupt collapse of the retaining wall. Therefore, the adverse effect can be more observable in the present case.

Fig. 7 shows that the settlement increases with an increase in the collapsed height of the retaining wall. The piles group with a large embedment ratio $(L / d=20)$ is less affected by the soil movement than short piles $(L / d=10)$. The inclination angle $(\alpha)$ of the slip surface with major principal plane decreases and the width of the sliding surface increase with the height of the collapsed retaining wall. The active pressure reduces significantly with the height of the collapsed retaining wall due to the stress relief and an increase in the inclination angle [36, 37]. The plastic flow over the soil rises with an increase in the collapsed height, which induces negative skin friction. It leads to an increase in the magnitude of piles settlement. The point of application of resultant forces also goes downward with increasing collapse height, but after a certain height, it will not move further down [36]. However, the arching effect brings up the location of the resultant force [36, 37]. The effect of arching would be relatively more prominent in the case of progressive rotation of the retaining than the abrupt collapse of the retaining wall.

For a small collapsed height of the retaining wall, the developed initial strains are within elastic limits. The change in the prevailing stress intensified by increasing the height of the collapsed retaining wall. However, the change in depth of the sliding surface (plastic zone) becomes marginal after a certain collapsed height, especially in the case of a long pile. This stage is reached at the nominal height $\left(H_{c} / L\right)$ of 0.16 and 0.32 for piles of embedment ratio 20 and 10 respectively. Similar trends are recorded in pile groups placed parallel to the soil flow $(1 \times 2$ and $1 \times 3)$. However, the magnitude of settlement is relatively less as compared to piles placed perpendicularly to the soil flow. In a piles group placed parallel to the soil flow, the second row and third row piles are subjected to relatively more confining pressure. Also, the redistribution of load among piles is more significant when placed perpendicular to the retaining wall, which makes this configuration more advantageous than those placed parallel. A similar observation was made in the earlier studies about lateral deflection [14 17].

The behaviour of piles changes with the embedment height of a pile and it can be seen from Fig. 8 . In general, increasing the embedment depth increases the frictional resistance as well as end-bearing resistance up to a certain extent, and it reduces the settlement of piles group. The breakdown of the retaining wall induces negative skin friction, which significantly affects the frictional resistance of piles, this phenomenon is more intense in piles with a smaller length. The 


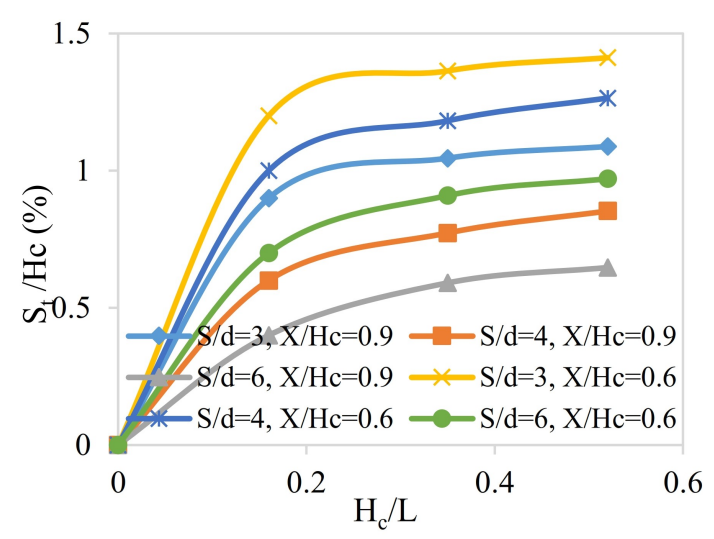

(a)

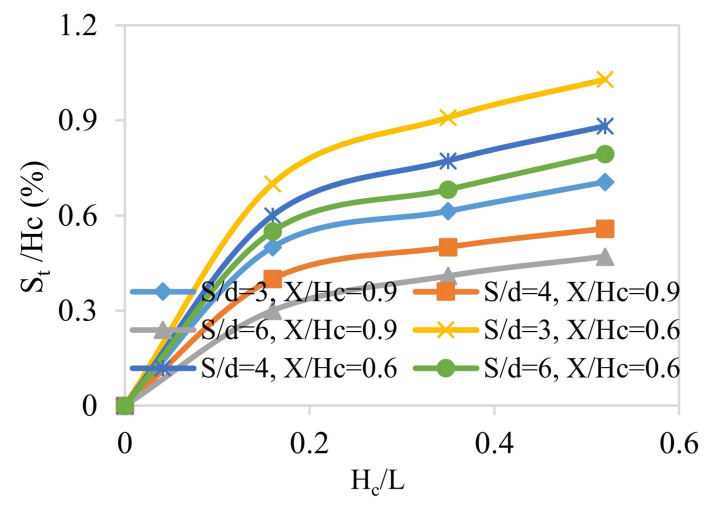

(c)

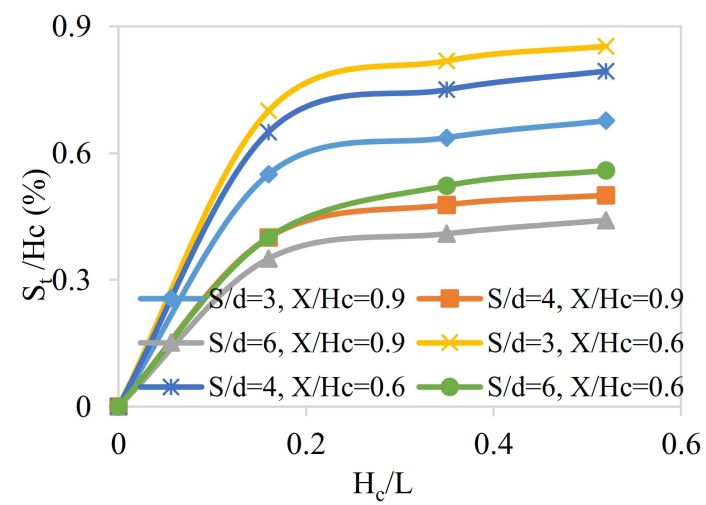

(e)

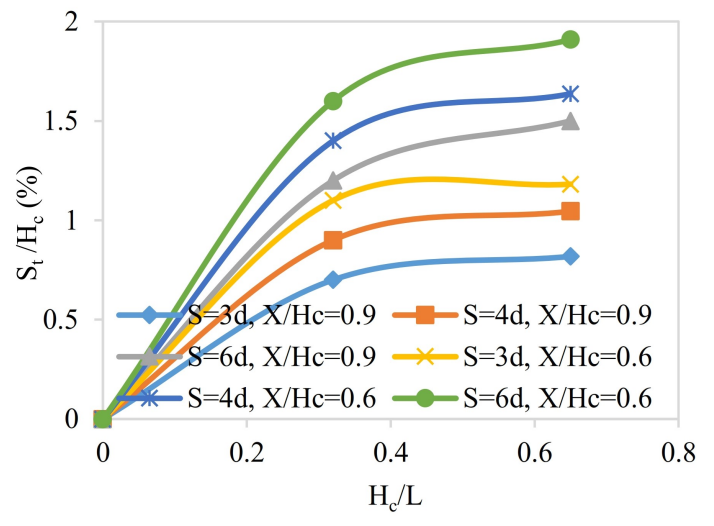

(b)

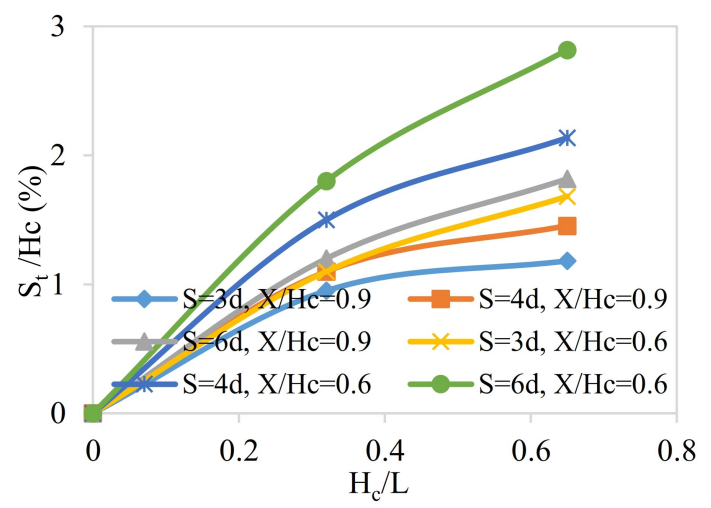

(d)

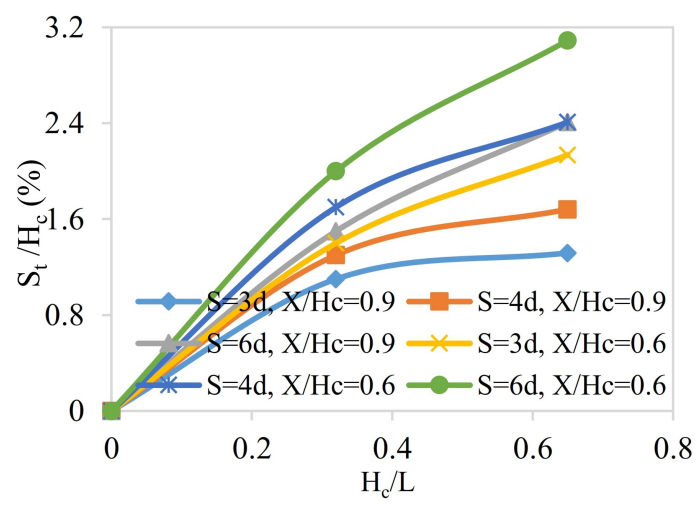

(f)

FiguRE 7. Effect of the collapsed height of the retaining wall: (a) $2 \times 1$ pile group, $L / d=20$, (b) $2 \times 1, L / d=10$, (c) $3 \times 1, L / d=20$, (d) $3 \times 1, L / d=10$, (e) $2 \times 2, L / d=20$, (f) $2 \times 2, L / d=10$. 


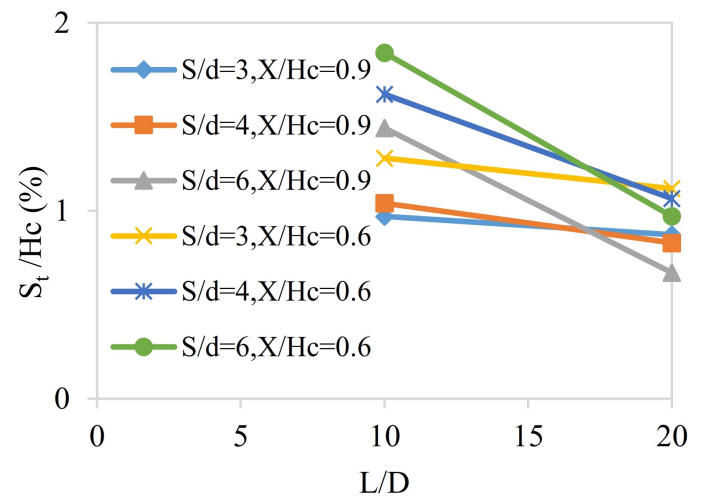

(a)

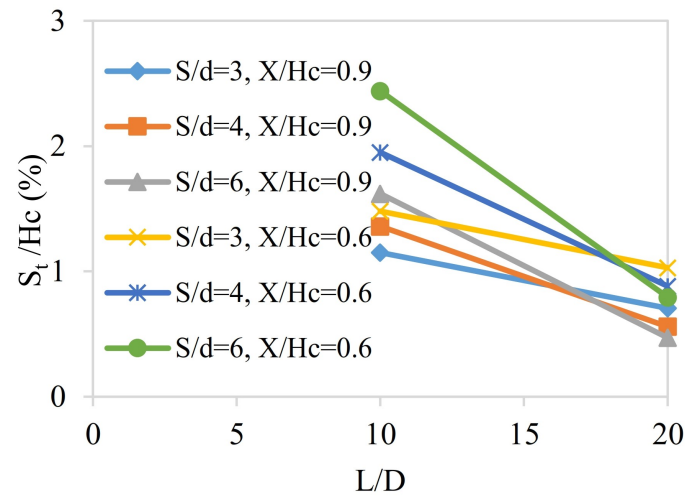

(b)

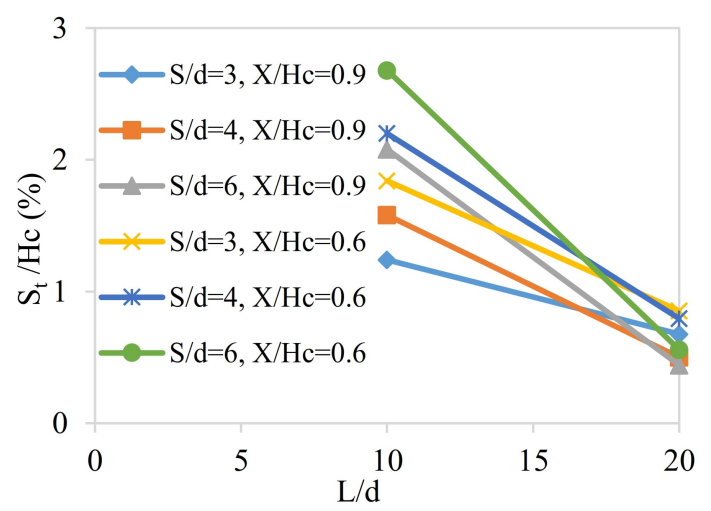

(c)

FiguRE 8. Effect of embedment ratio on the settlement: (a) $2 \times 1$, (b) $3 \times 1$ and (c) $2 \times 2$.

influence of embedment depth becomes more noticeable with an increase in the number and spacing of piles. The abrupt collapse of the retaining wall also reduces the end bearing, which is more visible in piles of small embedment depth. These factors together contribute to a higher settlement in smaller piles. The improvement in the load-carrying capacity with embedment depth is more noticeable in loose soil than in dense soil 38 . The reduction in the density of the foundation soil is relatively large in piles located close to the retaining wall. Therefore, the decrease in the settlement with the increase in the embedment ratio is more prominent in cases of piles resting near to the collapsed retaining wall.

Fig. 9 indicates that the settlement of pile groups decreases nonlinearly with an increase in distance $(X)$ of piles from the retaining wall. Piles placed near to the retaining wall or front piles are subjected to a higher stress level as compared to piles placed at a larger distance [2. In case of the abrupt collapse of the retaining wall, the sliding surface (plastic field) touches or passes through the piles, located even at a longer distance. However, in earlier studies, the retaining wall was either assumed to be stable or rotating gradually [9-15, 21]. Therefore, effects are not prominent as observed in the present study. The volume of the sliding mass as well as the velocity of soil movement near to the collapsed retaining wall is relatively large, which induces higher inertia force and moment on the piles. Consequently, piles settlement is also large in piles resting near to the collapsed retaining wall.

Increasing the distance between the retaining wall and piles enhances the piles-soil interface friction as well as prevailing confinement, which results in a decrease in the pile settlement (Fig. 9). Plastic state prevails above the sliding plane (active zone), but in the lower part, the soil remains at elastic state. In piles with longer embedment depth, the relative larger potions remain in an elastic state. Therefore, the effect of placement of piles relative to the retaining wall is more prominent in longer piles. This effect can be seen as the gradient of settlement plots shown in Fig. 8. Earlier studies also found that the settlement and lateral deflection are small if piles are located at a longer distance from the excavation surface [2, 15] [17, 28, 29].

Fig. 10 shows the variation in the settlement of piles with the change in the spacing of piles group. It can be seen that the settlement of piles group with spacing significantly varies depending on the embedment ratio $(L / d)$ of piles group. In the case of $L / d$ of 10 , the settlement increases with the spacing of the group (Fig. 9a). A similar effect was recorded by Shan et al. 30, 39. The soil arching effect diminishes with the increase in the spacing of row piles [40]. The decrease 


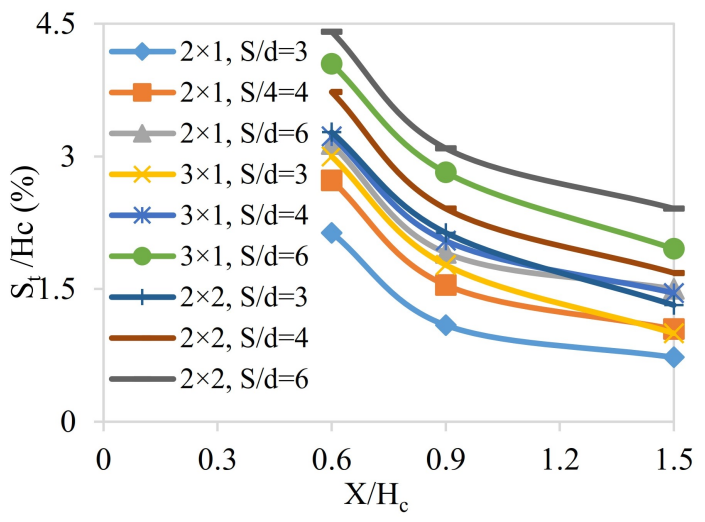

(a)

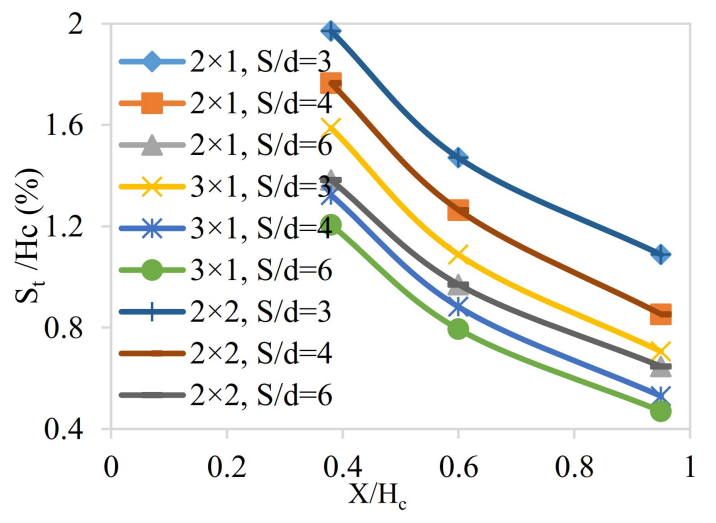

(b)

Figure 9. Effect of distance between retaining wall and pile groups; (a) $L / d=10$, (b) $L / d=20$.

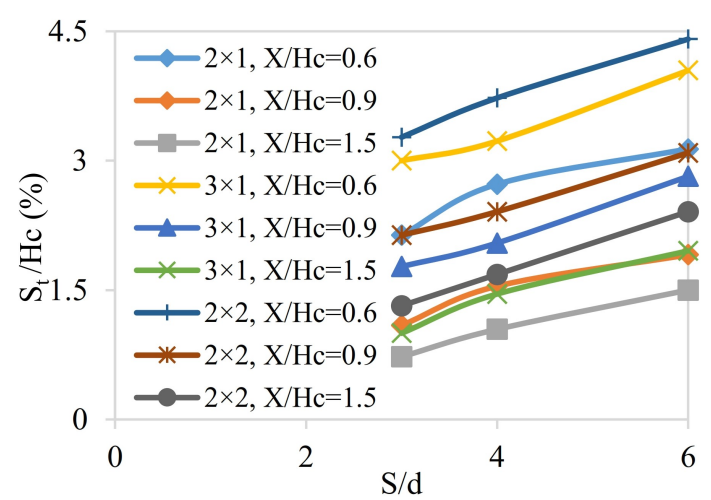

(a)

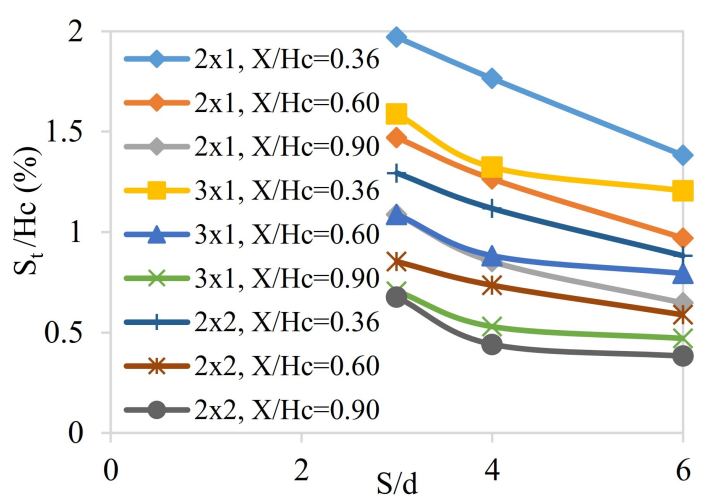

(b)

Figure 10. Effect of spacing on piles settlement: (a) $L / d=10$, (b) $L / d=20$.

in the soil arching effect reduces the piles capacity and increases the corresponding settlement. The piles response in the present case is dissimilar to active piles group response, where settlement reduces with an increase in spacing, irrespective of the embedment ratio. Contrary to piles with shorter piles, the settlement decreases with the increase in spacing in piles group with $L / d$ of 20 . The reduction in pile settlement might be contributed to enhanced end bearing capacity and shaft resistance with the increase in spacing. Mahmood and Abbas [34] also observed a reduction in the settlement with an increase in the spacing of piles with $L / d=40$. Unlike the variation in pile settlement, the lateral deflection always decreases with an increase in the pile spacing, irrespective of the pile embedment depth [17, 27, 28]. A separate detailed analysis can be carried out to analyse this difference in the behaviour of piles groups with different embedment depths.

The variation in pile settlement with the number of piles is shown in Fig. 11. The effect of the number of piles depends on the embedment ratio of the piles group. The settlement of piles increases for the embedment ratio 10 and decreases for the embedment ratio 20. A similar observation has been made in the case of a change in spacing (Fig. 11). In the case of large embedment ratio pile groups, the resistance is increasing with the increase in spacing and the increase in piles number. This may be attributed to the presence of arching and shielding effect in the case of a longer piles group. The piles group with small spacing and a higher number of piles behave like a continuous wall, which induces a shielding effect against the soil movement. Another reason might be contributed to redistribution of the load coming on rear piles after the breakdown of the retaining wall. This redistribution phenomena allows back piles to share more load and reduces the loads shared by the piles in a front row.

In piles with a small embedment depth $(L / d=10)$, the shielding and arching effect is either not developing or only partially developing. Also, the redistribution of the load is absent in piles with small embedment due to the presence of a very low confining pressure. Therefore, increasing piles number does not provide a positive effect. This phenomenon of load distribution is relatively significant in pile groups of $1 \times 2$ and $1 \times 3$, placed parallel to the direction of soil movement.

\section{Limitation AND FUtURE SCOPE}

As the testing was carried out on a small-scale model, the prevailing confining pressures and mobilised fric- 

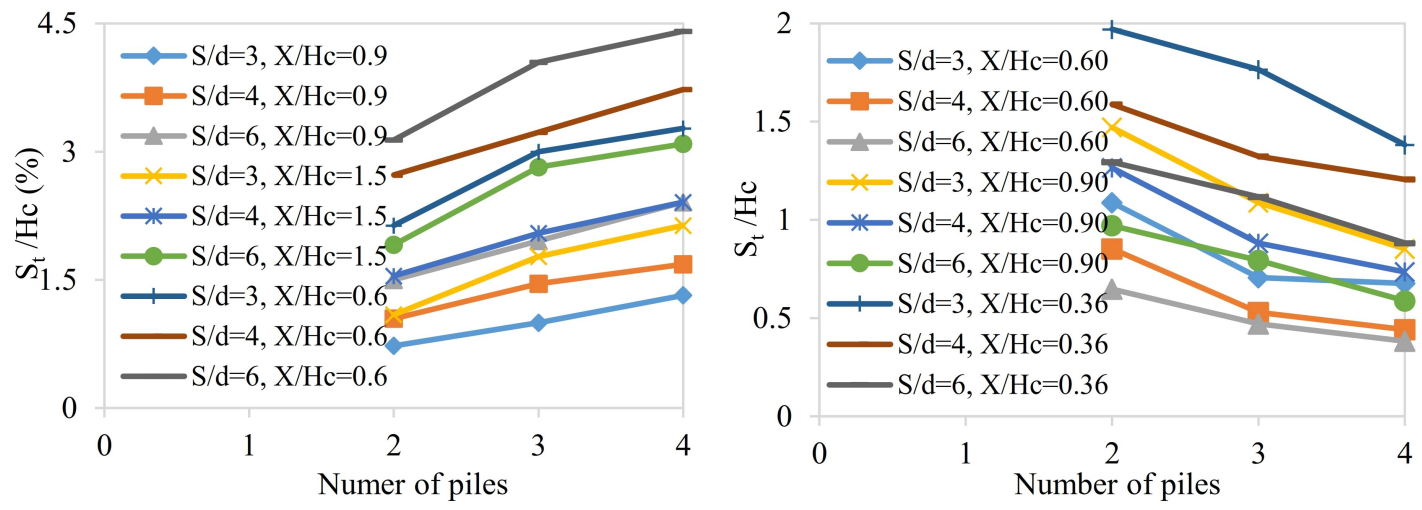

FIGURE 11. The variation in settlement with number of piles: (a) $L / d=10$, (b) $L / d=20$.

tion angles are less than those of prototype testing. The velocity of soil flow is also relatively higher in small scale model than the soil velocity in the prototype. Consequently, small scale piles may experience a higher settlement than piles in the field. The use of small-scale testing overestimates the severe effects of the breakdown of the retaining wall on piles. Though there can be differences in the results of the model testing and prototype quantitatively, nevertheless, the qualitative similarity (result trends) exists between the cases. Present study results reflect a short term effect of soil movement on piles, which is more critical in cohesionless soils. The results would have been different if clayey soil has been used to prepare the foundation bed as long term behaviour of cohesive soil is critical compared to the short term. Drainage condition further affects the behaviour of clayey soils. Effect of piles shapes may also be considered in future studies.

\section{Conclusion}

A laboratory model testing facility was developed to determine the settlement of piles group subjected to a sudden collapse of the retaining wall. Many factors affect the settlement of the pile. However, the height of retaining wall and embedment depth of the pile are the two most critical factors, affecting the settlement and performance of piles. The application of load on the pile increases the settlement significantly. The settlement is almost more than four times of the lateral deflection of the pile.

Irrespective of other factors, the settlement increases with an increased height of the collapsed retaining wall. The influence of the collapsed height is relatively more severe on the vertical component of the displacement than the lateral component in a single pile.

The settlement reduces with the increase in the distance of the pile from the retaining wall. The influence of piles' location relative to the retaining wall is more observable in the case of lateral displacement as compared to settlement.
The pile settlement decreases with an increase in the embedment depth of piles. In piles with the embedment ratio of 20 , the settlement reduces with an increase in spacing and piles number. However, the opposite trend is observed in piles with the embedment ratio of 10 . This might be due to the absence of the arching effect, especially in row piles placed parallel to the retaining wall.

The study results are limited to medium dense soil, and further detailed analysis is required to address the scaling effect. The study can be conducted on other soils and sand with different densities either in full scale or centrifuge testing. The influence of L/d can also be analysed by changing the diameter of piles.

\section{LIST OF SYMBOLS}

$d$ Pile diameter

$D_{l}$ Lateral displacement of pile

$H_{c}$ Critical collapse height of retaining wall

$H_{n}$ Height of $\mathrm{n}^{\text {th }}$ wooden shutter

$L$ Length of pile

$P$ Applied load

$S \quad$ Pile spacing

$S_{t} \quad$ Settlement of pile

$L / d$ Pile embedment ratio

$D / H_{c} \quad$ Normalised lateral displacement pile

$S / d$ Normalised spacing

$S_{t} / H_{c} \quad$ Normalised settlement of pile

$X / H_{c}$ Normalised distance between pile and retaining wall

\section{REFERENCES}

[1] E. E. De Beer, M. Wallays. Forces induced in piles by unsymmetrical surcharges on the soil around the piles. In 5th European Conf. on Soil Mech. and Foundation Eng., vol. 1. Madrid, 1972.

[2] D. E. L. Ong. Pile behaviour subject to excavation-induced soil movement in clay. Ph.D. thesis, Dept. of Civil Eng., NTU, Singapore, 2004.

[3] G. Hannink, A. F. van Tol. Large horizontal displacements of houses in Rotterdam. In Proc. 2nd Int. Conf. on Case Histories in Geot. Eng., pp. 1409 - 1415. St. Louis, Missouri, 1988. 
[4] R. J. Finno, S. A. Lawrence, N. F. Allawh, I. S. Harahap. Analysis of performance of pile groups adjacent to deep excavation. Journal of Geotechnical Engineering 117(6):934 - 955, 1991. DOI:10.1061/(ASCE)0733-9410(1991)117:6(934)

[5] H. Poulos. Failure of a building supported on piles. In Proc. Int. Conf. on Foundation Failures, pp. 53 - 66. Singapore, 1997.

[6] N. Thasnanipan, A. W. Maung, P. Tanseng. Damages to piles associated with excavation works in bangkok soft clay. In The Sixth Int. Conf. on Problems of Pile Foundations Building. Russia, 1998.

[7] S. T. Kok, B. Huat, J. Noorzaei, et al. A case study of passive piles failure in open excavation. DFI Journal: The Journal of the Deep Foundations Institute 3(2):50 57, 2009. DOI:10.1179/dfi.2009.011

[8] B.-T. Kim, G.-L. Yoon. Laboratory modeling of laterally loaded pile groups in sand. KSCE Journal of Civil Engineering 15(1):65 - 75, 2011. DOI:10.1007/s12205-011-0924-3.

[9] R. Zhang, J. Zheng, H. Pu, L. Zhang. Analysis of excavation-induced responses of loaded pile foundations considering unloading effect. Tunnelling and Underground Space Technology 26(2):320 - 335, 2011. DOI:10.1016/j.tust.2010.11.003.

[10] D. E. L. Ong, C. F. Leung, Y. K. Chow. Behavior of pile groups subject to excavation-induced soil movement in very soft clay. Journal of Geotechnical and Geoenvironmental Engineering 135(10):1462 - 1474, 2009. DOI:10.1061/(ASCE)GT.1943-5606.0000095.

[11] A. T. C. Goh, K. S. Wong, C. I. Teh, D. Wen. Pile response adjacent to braced excavation. Journal of Geotechnical and Geoenvironmental Engineering 129(4):383 - 386, 2003. DOI:10.1061/(ASCE)1090-0241(2003)129:4(383)

[12] L. T. Chen, H. G. Poulos. Piles subjected to lateral soil movements. Journal of Geotechnical and Geoenvironmental Engineering 123(9):802 - 811, 1997. DOI:10.1061/(ASCE)1090-0241(1997)123:9(802)

[13] C. F. Leung, Y. K. Chow, R. F. Shen. Behavior of pile subject to excavation-induced soil movement. Journal of Geotechnical and Geoenvironmental Engineering 126(11):947 - 954, 2000. DOI:10.1061/(ASCE)1090-0241(2000)126:11(947)

[14] C. F. Leung, J. K. Lim, R. F. Shen, Y. K. Chow. Behavior of pile groups subject to excavation-induced soil movement. Journal of Geotechnical and Geoenvironmental Engineering 129(1):58 - 65, 2003. DOI:10.1061/(ASCE)1090-0241(2003)129:1(58)

[15] D. E. Ong, C. E. Leung, Y. K. Chow. Pile behavior due to excavation-induced soil movement in clay. i: Stable wall. Journal of Geotechnical and Geoenvironmental Engineering 132(1):36 - 44, 2006. DOI:10.1061/(ASCE)1090-0241(2006)132:1(36)

[16] C. F. Leung, D. E. Ong, Y. K. Chow. Pile behavior due to excavation-induced soil movement in clay. ii: Collapsed wall. Journal of Geotechnical and Geoenvironmental Engineering 132(1):45 - 53, 2006. DOI:10.1061/(ASCE)1090-0241(2006)132:1(45)
[17] R. Shukla. Pile groups subjected to abrupt collapse of retaining structure. Gradevinar 70(11):953 - 564, 2018. DOI:10.14256/JCE.1626.2016.

[18] Z. Sabzi, A. Fakher. 3D response of an excavation adjacent to buildings supported by inclined struts. Acta Geotechnica Slovenica 14(1):38 - 53, 2017.

[19] F. Liang, F. Yu, J. Han. A simplified analytical method for response of an axially loaded pile group subjected to lateral soil movement. KSCE Journal of Civil Engineering 17(02):368 - 376, 2013. DOI:10.1007/s12205-013-1816-5.

[20] H. G. Poulos, L. T. Chen. Pile response due to excavation-induced lateral soil movement. Journal of Geotechnical and Geoenvironmental Engineering 123(2):94 - 99, 1997. DOI:10.1061/(ASCE)1090-0241(1997)123:2(94).

[21] B. U. Uge, G. Y. Cheng. Research progress on the influence of deep foundation pit excavation on adjacent pile foundation. In Ninth Intl. Conf. on Advances in Civil, Structural and Mechanical Engineering. Rome, Italy, 2019. DOI:10.15224/978-1-63248-182-5-03

[22] Q. N. Pham, S. Ohtsuka, K. Isobe, Y. Fukumoto. Group effect on ultimate lateral resistance of piles against uniform ground movement. Soils and Foundations 59(1):27 - 40, 2019. DOI:10.1016/j.sandf.2018.08.013.

[23] D. H. Do, T. A. Pham. Investigation of performance of soil-cement pile in support of foundation systems for high-rise buildings. Civil Engineering Journal 4(2):266, 2018. DOI:10.28991/cej-030990

[24] H. Li, S. Liu, L. Tong. Evaluation of the lateral response of single piles to adjacent excavation from CPT data. Canadian Geotechnical Journal 56(2):236 248, 2019. DOI:10.1139/cgj-2018-0131

[25] M. Malhotra, V. Sahu, A. Srivastava, A. Misra. Impact of pile foundations adjacent to tunnels in sandy stratum. Sadhana 44(8):1 - 11, 2019. DOI:10.1007/s12046-019-1169-y.

[26] F. Zhang, X. Wang, L. Li. A simplified algorithm of bending moment for passive pile. Journal of Physics: Conference Series 1176(5):1 - 6, 2019. DOI:10.1088/1742-6596/1176/5/052061

[27] S. W. Jacobsz, J. R. Standing, R. J. Mair, et al. Centrifuge modelling of tunnelling near driven piles. Soils and Foundations 44(1):49 - 56, 2004. DOI: $10.3208 /$ sandf.44.49

[28] R. Zhang, J. Zheng, S. Yu. Responses of piles subjected to excavation-induced vertical soil movement considering unloading effect and interfacial slip characteristics. Tunnelling and Underground Space Technology 36:66 - 79, 2013 DOI:10.1016/j.tust.2013.02.005

[29] R. P. Shukla, N. R. Patra. Settlement of pile groups exposed to excavation induced soil movement. Electronic Journal of Geotechnical Engineering 20(10):4293 - 4304, 2015.

[30] H. Shan, T. Xia, Y. U. Feng. Settlement of pile groups associated with excavation beneath existing basement. Chinese Journal of Geotechnical Engineering 37:46 - 50, 2015. DOI:10.11779/CJGE2015S1010 
[31] C. Y. Chen, G. R. Martin. Soil-structure interaction for landslide stabilizing piles. Computers and Geotechnics 29(5):363 - 386, 2002. DOI:10.1016/S0266-352X(01)00035-0

[32] B. C. Chattopadhyay, P. J. Pise. Ultimate lateral resistance of piles. Int Journal of Structures 6(3):113 $12,1986$.

[33] M. Pashayan, G. Moradi. Experimental investigation on efficiency factor of pile groups regarding distance of piles. Civil Engineering Journal 5(8):1812 - 1819, 2019. DOI:10.28991/cej-2019-03091373.

[34] A. K. Mahmood, J. M. Abbas. The effect of vertical loads and the pile shape on pile group response under lateral two-way cyclic loading. Civil Engineering Journal 5(11):2377 - 2391, 2019. DOI:10.28991/cej-2019-03091418.

[35] Y. Fang, I. Ishibashi. Static earth pressures with various wall movements. Journal of Geotechnical Engineering 112(3):317 - 333, 1986. DOI:10.1061/(ASCE)0733-9410(1986)112:3(317)
[36] Y. jian Lin, F. quan Chen, J. tao Yang, D. Li. Active earth pressure of narrow cohesionless backfill on inclined rigid retaining walls rotating about the bottom. International Journal of Geomechanics 20(7):04020102, 2020. DOI:10.1061/(ASCE)GM.1943-5622.0001727.

[37] D. Li, W. Wang, Q. Zhang. Lateral earth pressure behind walls rotating about base considering arching effects. Mathematical Problems in Engineering 2014:1 7, 2014. DOI:10.1155/2014/715891.

[38] H. G. Poulos, E. H. Davis. Pile foundation analysis and design. John Wiley and Sons, New York, 1980.

[39] H. Shan, X. Liu, X. Zhan, T. Xia. Settlement of pile group foundation associated with excavation beneath basement of existing building. Electronic Journal of Geotechnical Engineering 20(2):479 - 489, 2015.

[40] Z. Bo, Z. Yong-chao. Influence of space of double row piles on soil arching effect. Journal of Engineering Research and Applications 5(2):19 - 21, 2015. 